\title{
Teaching the Past Perfect: A Comparison of Two Approaches
}

\author{
Mehran Esfandiari ${ }^{1, *} \&$ David Rath ${ }^{1}$ \\ ${ }^{1}$ Academic Intensive English Program, Concordia University Irvine, Irvine, CA, USA \\ *Corresponding author: Department of Global Programs, Concordia University Irvine, Irvine, CA 92612, USA. \\ E-mail: mehran.esfandiari@cui.edu
}

Received: November 5, 2014

Accepted: November 19, 2014

Online Published: November 25, 2014

doi:10.5430/wjel.v4n4p12

URL: http://dx.doi.org/10.5430/wjel.v4n4p12

\begin{abstract}
This article discusses ways in which grammar teaching has been changing over the past few decades. Special attention is given to recent scholarship focusing on teaching the Past Perfect, a challenging area of English grammar for non-native speakers to master. A quasi-experimental case study is presented, comparing the effectiveness of two approaches - one using inductive techniques, and the other, a combination of inductive and deductive techniques. After a statistical analysis of the data collected, we conclude that the pedagogical grammar approach appears to be significantly more efficient than the inductive approach alone.
\end{abstract}

Keywords: the Past Perfect; pedagogical grammar; descriptive grammar; prescriptive grammar; CLT

\section{Introduction}

Grammar - that set of rules governing syntax and morphology which enables users to put words together to convey meaning - has been a primary concern in language teaching. Indeed, only in the 1970s did the grammar-translation method give way to other methods. Nowadays, though Communicative Language Teaching (CLT) dominates listening, speaking, reading and writing pedagogy, language programs still tend to include the direct study of grammar. Meanwhile, grammar pedagogy continues to be debated, some favoring prescriptive approaches, others supporting descriptive ones. The trend, however, is away from sentence-level and toward discourse level focus. Non-native speakers often find the Past Perfect to be one of the most difficult grammatical areas in the English language to master. They can find it difficult to identify the time orientation. They may confuse the Past Perfect with the Simple Past, the Past Continuous, or even the Present Perfect since all of them are used to describe past events. Therefore, the main aim of this study is to present the results of a case study into the effectiveness of two approaches in teaching the Past Perfect. In doing so, it suggests that pedagogical grammar appears to be more efficient than the inductive approach to a significantly large extent.

\section{Literature Review}

\subsection{Grammar: Knowledge or Skill?}

Where providing an accurate description of grammar is concerned, taking grammar into account as either knowledge or skill is the subject of heated debate. From a psychological point of view, grammar can be attributed not only to declarative, but also to procedural knowledge. In other words, it is associated with both the system and the use of language.

Contrary to formal linguistics, wherein grammar is treated as a context-free knowledge, the language socialization hypothesis suggests that grammar skill is acquired through repeated and meaningful experience with contextualized discourse. This is a process where interaction paves the way for grammar to act as a structural resource without being explicitly analyzed (Celce-Murcia, 2002). Indeed, having attached significance to skill development as a question of practice, Larsen-Freeman (2003) lays great emphasis on grammar as the fifth language skill. She argues that although grammar rules provide a sense of security and guidance on how language is structured, their usefulness might be restricted as students deal more with accuracy, less with meaningfulness, and rarely with appropriacy.

It is important to note that grammar is concerned with the use of correct function words. Not only does it play a 
crucial role in the construction and interpretation of texts, but it also contributes to discourse coherence and cohesion. Therefore, on these grounds, Larsen-Freeman (2003) advises teachers to re-create authentic acquisition conditions in their reading and writing classrooms.

\subsection{Approaches to Teaching Grammar}

Over the past few decades, teaching grammar has undergone a series of interesting movements as a great deal of attention has been paid to its role in the field of second language acquisition (SLA). In the past, the dominating approach was prescriptive grammar, in which providing straightforward rules was encouraged to help avoid making errors (Odlin, 1994). That is to say, appropriate English meant using sophisticated styles and implementing certain grammar rules. Such an approach begins with a list of certain items to be taught in sequence. Thus, the place of grammar within the traditional approach can be referred to as a kind of discipline (Crystal, 2004). Some suggest that it becomes an end in itself since it is mainly taught to ensure the accuracy of sentences and utterances (Yarrow, 2007). Indeed, the traditional approach encourages deductive grammar teaching and works on the assumption that once students have learned a structure, their productive language will make sense, not just grammatical sense. However, it might be argued that being exposed to one grammatical structure at a time does not guarantee that students will master the use of that particular grammatical item before moving on to a new one (Larsen-Freeman, 1997).

It is important to note that teaching grammar as an end in itself cannot be helpful. This is largely because it is not a tight clear-cut system like mathematics (Celce-Murcia, 1991). Leech (1994) believes in the inductive method of discovery learning - that is, going from data (or instances) to generalizations (or rules). In order for students to be capable of producing acceptable utterances spontaneously or communicatively, grammatical accuracy is not enough by itself (Ellis, 1997). Instead, grammar should be introduced to serve communicative purposes. It should always be taught with reference to a combination of meaning, social factors, and discourse. In other words, it has to be taken into consideration as a communicative end that is composed of three interrelated dimensions of form, meaning, and use (Celce-Murcia and Larsen-Freeman, 1999).

The question remains, should that "form, meaning, and use" be prescriptive or descriptive? Descriptive grammar refers to the structure of language as it is used by speakers and writers. It does not suggest how words have to be put together to make sentences. Instead, it describes how they are made by language users without mentioning whether or not it is good prescriptive usage (Celce-Murcia, 2002). Discourse analysis, on the other hand, focuses on the relationship between the language and the context in which it is used. It also considers the way language is used by members of certain social groups (Demo, 2001). Therefore, in order for learners to become completely familiar with a form or construction, contextual knowledge is of paramount importance as it paves the way for a deeper understanding of its function at the discourse level (Celce-Murica, 2002).

With a focus on process rather than product (Pennington, 1995) and a dynamic rather than static nature (Larsen-Freeman, 1997), modern pedagogical grammar in the field of English language teaching (ELT) encourages awareness-raising rather than practice-based activities (Celce-Murcia 1991). It encourages teachers to deviate from the traditional approach and concentrate their efforts on teaching grammar at the discourse level rather than the sentence level. It consists of two parts: the prescriptive part, which is about the articulation of a set of rules, and the descriptive part, which deals with grammatical analysis.

\subsection{The Past Perfect Characteristics}

It is interesting to note that sometimes 'the Past Perfect' comes under the name of 'the Pluperfect' or 'the Past Perfective'. Garner (2003) and Richards (2005) point out that it is used to refer to an action that occurred before another action in the past. They make a list of its main features as follows:

\subsubsection{Syntactic Characteristics}

From a syntactic point of view, two elements are required to form the Past Perfect, the past form of the auxiliary verb 'have' to act as an indicator of the past tense followed by the past participle of the main verb to complete the action.

\subsubsection{Semantic Characteristics}

The two indicators of time in the Past Perfect may cause confusion due to the fact that they refer to two actions that had already taken place. Therefore, enough attention should be drawn to an awareness of the time orientation in this particular tense. That is to say, it is important to ensure that learners are aware that the Past Perfect is used to indicate the first action. 


\subsubsection{Pragmatic Characteristics}

Where communicating information is concerned, the Past Perfect has the potential to act as a helpful device. This is because it makes it possible to establish the time framework of past events while taking into account the time difference between them.

\subsection{Approaches to Teaching the Past Perfect}

Where deductive approaches are concerned, grammar is looked upon as a clear-cut system like mathematics. Based on grammatical rules, they encourage the process of going from generalizations to instances. Since students may confuse the Past Perfect with the Simple Past, the Past Continuous, or even the Present Perfect, it is the responsibility of the teacher to provide learners with a clear explanation of the Past Perfect (Christianson, 1995).

Many practitioners of the deductive approach recommend that teachers take advantage of students' prior knowledge of the Past Perfect in a particular language to teach it more effectively in the English language. However, they are advised to do so preferably in countries where English is taught as a foreign language - that is, it is not the first language of communication. It is argued that reflection on constructs in a mother tongue can come to the aid of the teacher and facilitate the process of learning another language (Garner, 2003). Therefore, if this grammar area is taught to learners on the basis of their prior knowledge of the tense in their own language, they may find it easier to use that more effectively (Christianson, 1995). However, it needs to be emphasized that its counterpart needs to bear a striking resemblance to that of the English Past Perfect. Thus, unfortunately, this strategy is unhelpful for English language learners where verb tenses do not exist at all (e.g. most East and Southeast Asian Languages).

Inductive approaches, on the other hand, teach grammar from the opposite direction. They follow the inductive method of discovery learning based on the movement from data to rules (Leech, 1994). To put it another way, they encourage going from instances to generalization. It might be argued that when it comes to teaching the past tenses, particularly the Past Perfect, such approaches can be proved to be effective (Pennington, 1995).

\section{Context Setting}

The study was conducted in LASC American Language and Culture, located in Southern California. Based on the Common European Framework of Reference for Languages (CEFR), the school runs a broad range of English for Academic Purposes (EAP) courses in an accelerated fashion for a growing population of international students who come to the United States of America with the intention of gaining entry to undergraduate or postgraduate degree programs. As one of their core modules, grammar lessons are delivered to them twice a week in the form of two consecutive 50-minute sessions in blocks of twelve weeks.

\subsection{Materials}

For the purpose of this study, two popular commercial course books were selected. These were 'Interchange Third Edition' by Jack C. Richards and 'New Cutting Edge' by Sarah Cunningham and Peter Moor. Both of the textbooks were published in the year 2005 by Cambridge University Press and Pearson Longman, respectively. It is important to note that they both approach the Past Perfect at the intermediate level.

\subsection{Research Design}

A quasi-experimental study was conducted across a one-week period at LASC American Language and Culture with a control group, an experimental group, a pre-test, and a post-test. It should also be mentioned that a great deal of attention was paid to the timetabling, process of random sampling, and use of reliable tests to make sure that both of the groups would benefit from equivalent circumstances. Furthermore, the same teacher taught both of the control and experimental groups. And finally, the t-Test was applied at not only the outset, but also the end of the study to ensure internal reliability.

\subsection{Data Collection Instrument}

The Azar-Hagen Grammar Series (Fourth Edition) is a three-level grammar course published by Pearson Longman. Since all of the participants were intermediate learners, the test bank for the third level - which is known as 'Understanding and Using English Grammar' by Kelly Roberts Weibel (2009) - was used as the assessment pack. It has two tests, numbered as Test 1 and Test 2, to examine students' knowledge of the Past Perfect. Each test is made up of 27 questions in the form of completion tasks and multiple-choice questions. Test 1 was used as the pre-test and Test 2 as the post test for both the control group and the experimental group. 


\section{Participants and Sampling}

The subjects of this study were 24 learners from Japan, China, and South Korea. Although they appeared to be a homogeneous group at the intermediate level, we decided to rely on my experience as an ESOL examiner to confirm this. We conducted face-to-face interviews with them, which resulted in us realizing that with the exception of two Japanese ladies who were noticeably more advanced than others, the rest of the students were at the same level. Therefore, we divided them into two groups of 12 and assigned one of the two Japanese ladies to either of the groups.

At the next stage, the control group and the experimental group sat the pre-test, Test 1 . To ensure internal reliability, it was important to draw a comparison between the total mean scores of the two groups. Thus, the pre-test results were analyzed though the t-Test. Table 1 summarizes the calculations for the t-Test.

Table 1. Calculations for the t-Test

\begin{tabular}{lccc}
\hline & Mean & SD & Variance \\
\hline Group A & 10.41 & 1.31 & 1.71 \\
Group B & 9.83 & 1.26 & 1.60
\end{tabular}

Having calculated the t-value to be -1.1 , set the alpha level (the risk level) at 0.05 , and determined the degree of freedom (df), 22, the t-value can be looked up in a standard table of significance. From a statistical point of view, the t-value is too small and no marked difference can be found between the means of the two groups. Simply stated, the samples had been drawn from the same population. Therefore, Group A and Group B made the control group and experimental group, respectively. Now, it was time for both of the groups to be taught the Past Perfect by the same teacher over a one-week period.

\section{A Comparison of the Two Course Books}

Where inductive methods of teaching the Past Perfect are concerned, teachers should not simply give out the rule (Willis, 2008). Instead, learners should be given the opportunity to explore that through a journey of self-discovery with the aid of sufficient examples provided by the teacher. The book 'New Cutting Edge' from Longman ELT, which adopts an inductive approach to teaching the Past Perfect, was used to deliver the lesson to the control group.

It starts with a story-telling activity, which calls for group work. It reflects the advice of Celce-Murcia and Hilles (1988) with regard to the use of such activities for teaching the Past Perfect in an inductive way. Furthermore, in order for the activity to be more effective, a picture has been used to fit in with the idea put forward by Scrivener (2005), who believes that pictures and picture stories are very helpful for focusing on particular language points above all the past tenses. The second activity, however, includes an analysis. It not only provides an explanation of the Past Perfect, but also encourages learners to contrast it with the Simple Past in terms of the form of the verb. It is followed by a matching task, which has been designed to enable students to broaden their knowledge of the Past Perfect by figuring out when and how to use it in communication. Finally, the book rounds it off with an activity in the form of a puzzle to be performed in pairs. This parallels the idea proposed by Pennington (1995), who believes that grammar games enliven the classroom atmosphere while leaving time for the teacher to observe learners' performance.

On the other hand, the book 'Interchange Third Edition', which adopts an entirely different approach, was assigned to the experimental group. Based on the idea of communicative competence offered by Hymes (1971), Interchange sticks to communicative language teaching (CLT). The author, Richards (2005), asserts that the philosophy of this book is that English is best learned when used for meaningful communication. However, when it comes to teaching the Past Perfect, modern pedagogical grammar seems to have been applied. Simply stated, it appears to be a blend of deductive and inductive techniques. At the first stage, the text reflects the position of Thornbury (1999), who argues that the Past Perfect can be seldom found in isolation and always co-exists with other tenses. A context has been provided in the form of a conversation, which puts together the Simple Past, the Past Continuous, and the Past Perfect. Therefore, it can be argued that it can help to establish the time framework of the past events.

The next exercise provides a clear explanation of the Past Perfect as well as its syntactic characteristics to avoid confusion. In addition, some example sentences have been selected from the context of the conversation in the previous exercise to raise awareness of the time difference between the Simple Past, the Past Continuous, and the Past Perfect. At the next stage, there is a sentence-completion task where all three types of the past tense are required 
to be put together in different contexts. It can help learners to develop a deeper understanding of the Past Perfect in unison with the time orientation of other past events. Finally, there is a matching task to make complete stories out of those contexts and an opportunity for learners to produce some sentences using the correct form of the past tense.

\section{Results}

At the end of the week, the control group and the experimental group sat the post-test, Test 2. Once again, a comparison had to be drawn between the total mean scores of the two groups. Therefore, the results of the post-test were painstakingly analyzed through the t-Test. Table 2 summarizes the calculations for the t-Test.

Table 2. Calculations for the t-Test

\begin{tabular}{lccc}
\hline & Mean & SD & Variance \\
\hline $\begin{array}{l}\text { Control Group } \\
\text { (Group A) }\end{array}$ & 19.91 & 1.24 & 1.53 \\
$\begin{array}{l}\text { Experimental Group } \\
\text { (Group B) }\end{array}$ & 23.50 & 1.44 & 2.09 \\
\hline
\end{tabular}

Having calculated the t-value to be 6.5 , set the alpha level (the risk level) at 0.05 , and determined the degree of freedom (df), 22, the t-value can be looked up in a standard table of significance. From a statistical point of view, the $\mathrm{t}$-value is found to be substantially large. Therefore, there is significant difference between the mean scores of the control group and the experimental group, which confirms that the samples have been drawn from different populations.

\section{Discussion of the Results}

The initial t-Test confirmed the existence of only a slight group difference at the beginning of the study. However, it confirmed a significantly distinct group difference at the end of the study. By making a comparison between the pre-test and post-test mean scores of the control group and the experimental group, it is obvious that the experimental group did significantly better than the control group in terms of correct use of the Past Perfect. Therefore, it can be argued that the pedagogical approach is far more effective than the inductive approach.

\section{Conclusion}

The quasi-experimental case study described above, comparing the effectiveness of the two approaches - one using inductive techniques, and the other, a combination of inductive and deductive techniques - presented a strong, data-driven case in favor of pedagogical grammar. To ensure validity, careful timetabling, random sampling, and a reliable pre-test provided equivalent circumstances for both the control group and the experimental group. Furthermore, the same teacher, familiar with both approaches, taught both groups. Afterward, a reliable post-test, followed by a statistical analysis showed that the combined approach was significantly more efficient than the inductive approach. However, there is clearly a need for further research on this topic area.

\section{References}

Celce-Murcia, M. (1991). Grammar pedagogy in second and foreign language teaching. TESOL Quarterly, 25(3), 459-480. http://dx.doi.org/10.2307/3586980

Celce-Murcia, M. (2002). Why it makes sense to teach grammar in context and through Discourse. In Hinkel, E. and Fotos, S. (eds.), New Perspectives on Grammar Teaching in Second Language Classrooms. Mahwah, NJ: Lawrence Eribaum. PP. 119-133.

Celce-Murcia, M., \& Hilles, S. (1988). Techniques and resources in teaching grammar. New York: Oxford University Press.

Celce-Murcia, M., \& Larsen-Freeman, D. (1999). The grammar book: An ESL/EFL teacher's course (2nd ed.). Boston: Heinle. 
Christianson, K. (1995). The past perfect tense in English and German: Using one to teach the other. Paper presented at JALT Southwest Region Conference (May 14, 1995, Kitakyushu, Japan). ERIC Doc. \#ED 383203.

Crystal, D. (2004). Making Sense of Grammar. Pearson Education, England.

Crystal, D. (2004). Rediscover Grammar (3rd Edition). Pearson Education, England.

Cunningham, S., \& Moor, P. (2005). New Cutting Edge Intermediate. Longman Pearson.

Demo, D. (2001). Discourse analysis for language teachers. ERIC Educational Report, ERIC Digest. EDO-FL-01-07. Retrieved 5 April 2011 from http://www.cal.org/resources/Digest/digest_pdfs/0107-demo.pdf

Ellis, R. (1997). SLA research and language teaching. Oxford: Oxford University Press.

Garner, B.A. (2003). Garner's Modern American Usage (2nd Edition). Oxford: Oxford University Press.

Hymes, D. (1971). Competence and performance in linguistics theory. In R.Huxley \& E. Ingram (Eds.), Language Acquisition: Models and Methods. London: Academic Press.

Larsen-Freeman, D. (1997). Chaos/complex science and second language acquisition. Applied Linguistics, 18(2), 141-165. http://dx.doi.org/10.1093/applin/18.2.141

Larsen-Freeman, D. (2003). Teaching language: from grammar to grammaring. Boston: Thomson/Heinle. Chapter 2 'Challenging conceptions of grammar'. PP. 11-23.

Leech, G. (1994). Students' grammar - teachers' grammar - learners’ grammar. In Bygate, M., Tonkyn, A., \& Williams, E. (eds.), Grammar and the language teacher. Harlow: Longman. PP. 17-30.

Odlin, T. (1994). Introduction to Odlin, T. (ed.), Perspectives on pedagogical grammar. Cambridge: Cambridge University Press. PP. 1-22.

Pennington, M.C. (1995). New ways in teaching grammar. Alexandria, Va: TESOL.

Richards, J.C. (2005). Interchange Third Edition. Cambridge: Cambridge University Press.

Scrivener, J. (2005). Learning Teaching (second edition). Oxford: Macmillan Education.

Thornbury, S. (1999). How to teach grammar. Harlow, Essex: Pearson Education Limited.

Weibel, K.R. (2009). Test Bank for Understanding and Using English Grammar (4 ${ }^{\text {th }}$ Edition). New York: Pearson Longman.

Willis, D. (2008). More about the Past Perfect. [online]. London: British Council. Retrieved 7 April 2011 from: http://www.teachingenglish.org.uk/blogs/dave-willis/more-about-past-perfect

Yarrow, R. (2007). How do students feel about grammar?: The framework and its implications for teaching and learning. Changing English: Studies in Culture and Education, 14(2), 175-186. http://dx.doi.org/10.1080/13586840701443008 